\title{
pro.posições
}

http://dx.doi.org/10.1590/1980-6248-2019-ed02

$e$-ISSN 1980-6248

DOSSIÊ "Pro-Posições 30 anos"

\section{Pro-Posições de outrora e de hoje ${ }^{1,2}$ \\ Pro-Posições once and today}

André Luiz Paulilo (i)

Sílvio Donizetti de Oliveira Gallo (ii)

\begin{abstract}
(i) Universidade Estadual de Campinas - UNICAMP, Campinas, SP, Brasil. https://orcid.org/00000001-8112-8070,paulilo@unicamp.br

(ii) Universidade Estadual de Campinas - UNICAMP, Campinas, SP, Brasil. https://orcid.org/0000-

0003-2221-5160,gallo@unicamp.br.
\end{abstract}

Em março de 1990, a edição do primeiro número da revista Pro-Posições iniciou uma trajetória que hoje reúne 30 volumes publicados. A iniciativa se deu na Faculdade de Educação da Unicamp, à época dirigida por José Dias Sobrinho, e resultou do trabalho de uma comissão editorial integralmente formada por seus professores: Newton Aquiles Von Zuben, José Camilo dos Santos Filho, Marcia Regina Ferreira de Brito, Lucia Mercês de Avelar e Ezequiel Theodoro da Silva. Desde então, tanto prosperaram medidas de institucionalização da revista quanto providências para a sua qualificação editorial, o que implicou o trabalho de muitas pessoas e envolveu uma assídua atenção ao debate educacional das últimas três décadas, mas, também, aos protocolos editoriais de produção de periódicos científicos e aos parâmetros acadêmicos de avaliação nessa área da difusão dos resultados de pesquisa.

O reconhecimento dos resultados a que se pode chegar e da quantidade de trabalho exigido das pessoas envolvidas nessa iniciativa da Faculdade de Educação de manter um

\footnotetext{
1 Normalização, preparação e revisão textual: Leda Farah - farahledamaria@gmail.com e Vera Bonilha verabonilha@yahoo.com.br.

2 Texto integrante do Dossiê especial: "Pro-Posições 30 anos", organizado pelo Prof. Dr. André Luiz Paulilo (Editor Associado).
} 


\section{pro.posıções}

$e$-ISSN 1980-6248

http://dx.doi.org/10.1590/1980-6248-2019-ed02

periódico científico de prestígio na área da Educação animou a organização deste dossiê. Com o propósito de revisitar diferentes aspectos da história da Pro-Posições nos seus 30 anos de circulação, a Comissão Editorial debruçou-se sobre os volumes já publicados para propor uma forma de registro e apreciação do que está realizado. O que se segue como dossiê resultou da opção de reunir estudos de diferentes membros do Conselho Editorial sobre a revista e sobre os temas nela publicados. Ao modo de balanços do estado da arte ou a partir do estudo da história do periódico, as contribuições de Anderson Trevisan; André Paulilo; Helena Sampaio; Sílvio Gallo, Alexandre Filordi e Marcos Ribeiro de Santana; Norma Ferreira; e Carmen Lúcia Soares com Eliana Ayoub deixam ver diferentes aspectos da presença da Pro-Posições no debate educacional e de como sua relevância acadêmica foi construída.

Cumpre ressaltar que, embora os artigos tenham sido propostos pelos editores que aderiram à chamada deste dossiê comemorativo, à exceção daquele de Anderson Trevisan, escrito a convite, todos os textos passaram pelo sistema de avaliação duplo cego, tendo recebido ajustes e reformulações, quando os processos avaliativos assim indicaram. Logo, ainda que se trate de um dossiê comemorativo que foge à regra do cotidiano editorial da revista, ele não recebeu um tratamento diferenciado em termos de avaliação, tendo seguido a mesma trilha dos manuscritos submetidos de forma independente e daqueles que compõem dossiês propostos e aprovados pela comissão editorial.

O artigo que abre o dossiê dedica-se ao que há de pensamento na elaboração das capas da revista Pro-Posições. Anderson Trevisan analisa a proposta estética estabelecida pelas imagens, pelas fontes e pelas cores presentes nas capas publicadas pela Pro-Posições. Trilhando um caminho metodológico proposto por Pierre Francastel, chega a um questionamento inteiramente contemporâneo acerca do lugar das capas das revistas no mundo do periódico digital hoje.

Segue-se um estudo dos ciclos de vida da revista. André Paulilo se propôs a discutir os momentos em que a revista Pro-Posições repensou seu funcionamento e celebrou os resultados. A atenção aos momentos em que os editoriais enunciam mudanças no formato e na organização da produção da revista ou celebram o reconhecimento dos pares ou, então, as efemérides importantes, percebe diferentes fases editoriais ao longo das três décadas de circulação da ProPosições. A análise encontra nos modelos e nos protocolos editoriais, no suporte textual e em alguns testemunhos as fontes para uma reflexão acerca da "intrincada trama de fazeres e movimentações em torno da publicação de um periódico acadêmico". 


\section{pro.posıções}

http://dx.doi.org/10.1590/1980-6248-2019-ed02

$e$-ISSN 1980-6248

Já as análises de Helena Sampaio sobre a presença do tema do ensino superior na revista Pro-Posições resultam do primeiro balanço de estudos deste dossiê. O levantamento de textos, autores e conteúdos publicados no período de circulação desta revista foi posto em diálogo com a produção no campo de estudos e pesquisas acerca do ensino superior. No quadro que a análise delineia sobre a recorrência do tema na Pro-Posições se destacam, por um lado, a ousadia em abrir espaço para temas ainda incipientes nos anos 1990 e, por outro, a multiplicidade das abordagens a respeito do ensino superior ao longo da trajetória da revista.

Depois, Sílvio Gallo, Alexandre Filordi e Marcos Ribeiro de Santana reúnem e comentam a produção nos campos da Filosofia e da Filosofia da Educação, publicada na ProPosições. Encontram no conjunto então publicado mais que os fundamentos teóricos filosóficos para a educação, uma contínua crítica e revisão dos próprios fundamentos da educação. Suas conclusões dão conta dos efeitos que o apoio institucional e a dedicação do corpo editorial puderam gerar para o pensamento educacional. O olhar retrospectivo que os autores lançaram sobre a presença da reflexão filosófica na Pro-Posições também alcança tarefas atuais: insistir "nos marcadores fundamentais de uma sociedade livre e com direitos assegurados em sua ampla garantia para o livre pensamento, a livre expressão e as abordagens educacionais - claro está -, considerando a complexidade humana inerente a todos que compõem a sociedade".

Norma Sandra de Almeida Ferreira analisa os sentidos e significados dos estudos acerca da leitura publicados na Pro-Posições. Percebe que esta revista foi parte de um campo que se ampliou e diversificou na tentativa de compreender a leitura em sua complexidade de usos e práticas. Ao qualificar essa presença, Norma Ferreira mostra que na Pro-Posições "a leitura é tomada pela ideia de urgência e de importância inquestionáveis" e estudada com vistas à "melhoria das condições de promoção do uso e da partilha dos textos, numa sociedade profundamente desigual".

Finalmente, Eliana Ayoub e Carmen Lúcia Soares dedicaram atenção à produção acerca do e sobre o corpo, publicada na revista Pro-Posições. Analisaram uma centena de textos sobre a temática para atestar a pluralidade de perspectivas teóricas e metodológicas que a revista abriga e reconhecer a Pro-Posições "como um periódico da área da educação fortemente aberto ao diálogo amplo e qualificado, que contempla temas emergentes e originais". O acolhimento de estudos e pesquisas do e sobre o corpo na primeira década, a sua consolidação na década seguinte e a diversificação de perspectivas nessa área na última década são rastreados e 


\section{pro.posições}

http://dx.doi.org/10.1590/1980-6248-2019-ed02

$e$-ISSN 1980-6248

compreendidos por um estudo principalmente atento ao diálogo entre diferentes campos do conhecimento que o tema exige.

O dossiê Pro-Posições 30 anos deseja chamar a atenção para os resultados de um trabalho editorial já reconhecido pela sua relevância acadêmica na discussão da educação no País, sem deixar de também ser uma contribuição à reflexão de tudo aquilo que envolve a publicação de um periódico científico. Nesse sentido, o conjunto dos artigos assim reunidos aqui respondeu à necessidade de apreender algo das mudanças por que passou a revista Pro-Posições, interrogando diferentes modalidades de funcionamento do próprio campo educacional. No entanto, o interesse pelo conhecimento e pela sistematização das informações que os periódicos especializados em educação contêm e oferecem para a compreensão histórica não é recente. Pierre Caspard chega a atribuir esse interesse a Beurier (1889) e D’Alméras (1900). Mas é a partir do próprio Pierre Caspard (1981/1991) que toda uma série de iniciativas será organizada. Ao repertório analítico da imprensa periódica educacional francesa que dirigiu entre 1981 e 1991, seguiram-se iniciativas semelhantes em Portugal e no Brasil. De fato, as análises contidas neste dossiê acerca das três décadas da revista Pro-Posições enfrentaram preocupações que têm ocupado muitos pesquisadores e reunido um importante conjunto de reflexões ${ }^{3}$.

Por um lado, porque as revistas especializadas em educação configuram-se como fontes de informação para a compreensão de discursos, relações e práticas que balizam o campo educacional, são veículos nos quais se expressam tanto os desejos de futuro quanto a denúncia da situação presente. Segundo advertem Catani e Câmara (1997), constituem uma instância privilegiada para

a apreensão dos modos de funcionamento do campo educacional, pois fazem circular informações sobre o trabalho pedagógico, o aperfeiçoamento das práticas docentes, o ensino específico das disciplinas, a organização dos sistemas ... e outros temas que emergem do espaço profissional. (p. 7)

Dessa perspectiva, os periódicos educacionais contribuem para a compreensão do campo educacional em muitos aspectos da sua complexidade, ao mesmo tempo em que impõem aos pesquisadores importantes exigências de método.

3 Além do próprio Pierre Caspard e de Penelope Caspard-Karydis (1997), ver os trabalhos de Antonio Nóvoa (1997), Denice Catani (2003), Marta Carvalho (1998) e Pierre Ognier (1984). 


\section{pro.posıções}

http://dx.doi.org/10.1590/1980-6248-2019-ed02

$e$-ISSN 1980-6248

Por outro lado, as revistas especializadas em educação resultam da dinâmica de funcionamento do campo educacional, cujos diferentes aspectos esses materiais explicitam em si. De modo que, como observaram ainda Catani e Câmara (1997), atentar para o aparecimento e o ciclo de vida da imprensa periódica educacional permite "conhecer as lutas por legitimidade que se travam dentro do campo educacional e também a participação dos agentes produtores do periódico na organização do sistema de ensino e na elaboração dos discursos que visam a instaurar as práticas exemplares" (p. 7). Assim, como um objeto de estudo, as revistas especializadas em educação exprimem, desde as formas editoriais da sua realização, aspectos da cultura profissional à qual pertencem. $\mathrm{Na}$ ordem de questões que o estudo de materiais deste tipo então suscita não só importam, portanto, as informações que dão registro, mas, principalmente, as relações, as representações e as estratégias das quais são o resultado.

As análises nessa direção principalmente se ocuparam das revistas pedagógicas publicadas nas últimas décadas do século XIX e nas primeiras décadas do século XX. Dessa atenção já resultaram um importante acumulado de estudos acerca de múltiplos aspectos da organização do sistema público de ensino em diferentes estados do País e um melhor entendimento dos saberes pedagógicos que colocaram em circulação (Carvalho, 1998). A discussão e o debate educacional que se estabeleceram um século depois, entre as últimas décadas do século XX e as décadas iniciais do século XXI, ressentem-se de uma atenção do mesmo tipo. Desde que a produção acadêmico-científica se configurou em espaço privilegiado para a pesquisa e a reflexão sobre a educação, foram poucos e pontuais os esforços para também compreender o periodismo científico como expressão do funcionamento do campo educacional. No entanto, o catálogo Imprensa Periódica Educacional Paulista (1890-1996) (Catani \& Sousa, 1999) já apontava para essa possibilidade, do mesmo modo que, mais recentemente, os diferentes balanços de produção publicados em periódicos do mesmo gênero que a revista ProPosições (Editores, 2015; Lüdke, \& Boing, 2007). É nesse sentido que este dossiê, além de reconhecer a relevância dos resultados conseguidos em três décadas de publicação da ProPosições, deseja, igualmente, contribuir para o estudo do periodismo científico especializado em educação. À comissão editorial que formulou a proposta do dossiê e viabilizou sua organização e publicação, a análise crítica e o estudo criterioso das vicissitudes e das idiossincrasias das realizações do trabalho que hoje ela própria continua pareceram ser a melhor forma de celebrar os 30 anos de circulação da revista Pro-Posições. 


\section{pro.posıções}

$e$-ISSN 1980-6248

http://dx.doi.org/10.1590/1980-6248-2019-ed02

Neste momento de comemoração, os atuais editores de Pro-Posições não podem deixar de manifestar seu agradecimento a todas as pessoas que, nestes 30 anos, tornaram a revista possível. Aos editores-chefes: José Camilo dos Santos Filho, Agueda Bernardete Bittencourt, Luci Banks-Leite e Ana Maria Fonseca de Almeida que, com o apoio das mais de três dezenas de editores associados, docentes da FE-Unicamp e associados de outras instituições, do Brasil e do exterior, construíram e consolidaram a revista; às editoras-executivas Malu Arruda (de 2002 a 2013) e Roberta Pozzuto (desde 2013), que garantiram (e garante, no caso da atual editora) a operacionalização do periódico, atendendo aos editores, aos autores e a todo o público, sendo o "rosto" da revista; às revisoras Leda Maria de Souza Freitas Farah e Vera Lúcia Fator Gouvêa Bonilha, que com carinho, dedicação, competência e excelência profissional cuidaram da qualidade dos textos aqui publicados.

Ao completar esse ciclo de 30 anos, a comissão editorial de Pro-Posições espera que a revista possa seguir enfrentando os desafios que se impõem para o meio editorial acadêmico brasileiro, em especial num momento em que a educação superior pública e a pesquisa acadêmica são alvos de críticas de setores do governo e de setores da sociedade civil. A produção do conhecimento e sua circulação com seriedade e qualidade editorial são as armas de que dispomos para enfrentar tais ataques, e esperamos seguir sendo veículo da publicação de trabalhos investigativos rigorosos e de inequívoca qualidade no campo da Educação, como fontes de um pensamento crítico e criativo, que contribua para a sociedade e para o País.

\section{Referências}

Beurier, A. (1889). Les periodiques scolaires français de 1789 a 1889. Paris.

Caspard, P. (Dir.). (1981-1991). La presse d'education et d'enseignement, XVIII siècle-1940. Répertoire analytique (4 vols.). Paris: CNRS et INRP.

Caspard, P., \& Caspard-Karydis, P. (1997). Imprensa pedagógica e formação contínua de professores primários (1815-1939). In D. B. Catani, \& H. C. B. Câmara, Educação em revista: a imprensa periódica e a bistória da educação (pp. 33-46). São Paulo: Escrituras.

Catani, D. (2003). Educadores à meia luz: um estudo sobre a Revista de Ensino da Associação Beneficente do Professorado Público de São Paulo. Bragança Paulista: EDUSF. 


\section{pro.posıções \\ $e$-ISSN 1980-6248}

http://dx.doi.org/10.1590/1980-6248-2019-ed02

Catani, D., \& Câmara, H. C. B. (1997). Educação em revista: a imprensa periódica e a história da educação. São Paulo: Escrituras.

Catani, D. B., \& Sousa, C. P. (1999). O Catálogo da Imprensa Periódica Educacional Paulista (1890-1996): um instrumento de pesquisa. In D. B. Catani, \& C. P. Sousa (Orgs.), Imprensa Periódica Educacional Paulista (1890-1996) (Catálogo, pp. 9-23). São Paulo: Plêiade.

D’Alméras, H. (1900). Notes sur l'Histoire de la Presse de l'enseignement. Evreux: imp. de C. Hérissey.

Editores (2015, junho). Editorial. Revista de Sociologia e Política, 23(54), 03-08.

Lüdke, M., \& Boing, L. A. (2007, outubro). O trabalho docente nas páginas de Educação \& Sociedade em seus (quase) 100 números. Educação \& Sociedade, 28(100), 645-650.

Nóvoa, A. (1997). A imprensa de educação e ensino: concepção e organização do Repertório Português. In D. B. Catani, \& H. C. B. Câmara, Educação em revista: a imprensa periódica e a história da educação (pp. 11-31). São Paulo: Escrituras.

Ognier, P. (1984, março). L'ideologie des foundateurs et des administrateurs de L'École Républicaine à travers de la Revue Pédagogique, de 1878 a 1900. Revue Française de Pedagogie, (66), 7-14. 